\title{
Post-herpetic neuralgia was not frequent or severe after a first episode of herpes zoster
}

Helgason S, Petursson G, Gudmundsson S, et al. Prevalence of post-herpetic neuralgia after a first episode of herpes zoster: a prospective study with long term follow up. BMJ 2000 Sep:321:794-6.

\section{QUESTION: In patients with a first episode of herpes zoster, what is the clinical course of the disease and the duration of pain?}

Design

Inception cohort followed up for 12 months.

\section{Setting}

Catchment area of 100000 people for 62 general practitioners in Iceland.

\section{Patients}

421 patients \{mean age 42 y, $56 \%$ women $\}^{*}$ who had a first episode of herpes zoster. Patients with a history of zoster were excluded. Follow up was complete at 1 year.

\section{Assessment of prognostic factors \\ Sex and age.}

\section{Main outcome measures}

Severity and duration of pain and prevalence of post-herpetic neuralgia.

\section{Main results}

Sex was not a predictor of post-herpetic neuralgia at any point during follow up. Age was a predictor of pain severity and duration. The odds ratio for pain per 10 years of age difference was 1.87 (95\% CI 1.56 to 2.23) after 1 month, 2.11 (CI 1.56 to 2.84) after 3 months, and 2.33 (CI 1.48 to 3.69 ) after 12 months. In patients $<60$ years of age, the prevalence of post-herpetic neuralgia was low, and no patients had more than mild pain after 3 months (5 patients [1.8\%] after 3 mo; 2 patients [0.7\%] after $12 \mathrm{mo}$ ). In patients $\geqslant 60$ years of age, the frequency and severity of neuralgia increased. After 3 months, 23 patients (20\%) had pain, and 2 patients (1.7\%) had severe pain. After 12 months, 12 patients (9.4\%) had pain, but none had severe pain. None of a random sample of 183 patients who were free of neuralgia at 12 months reported any recurrence of pain during long term follow up (3.2 to 7.0 y). Among 14 patients (all ages) who reported pain after 12 months, 12 considered the pain mild.

Sources of funding: In part, Icelandic College of Family Physicians and Research Fund of the University of Iceland.

For correspondence: Dr $S$ Helgason, Arbaer Health Care Centre, IS-110 Reykjavik,

Iceland.on

sh@centrum.is.

\section{Conclusions}

In patients with a first episode of herpes zoster, the course of disease was benign among those $<60$ years of age. In older patients, the frequency of neuralgia increased, but pain severity was rarely more than mild. Patients free of pain had no pain recurrence.

*Information provided by author.

\section{COMMENTARY}

The community based, prospective study by Helgason et al of 421 patients with a first episode of herpes zoster found that the point prevalence of post-herpetic neuralgia after 1 month was only $19 \%$, after 3 months was $7 \%$, after 1 year was $3 \%$, and after 3 years was about $1 \%$. These results are consistent with previous community based studies, ${ }^{1}$ but are lower than the 3 month point prevalence estimates of $33 \%$ to $43 \%$ observed among patients enrolled in trials of antiviral agents who were allocated to placebo. ${ }^{2}$

The higher prevalence of post-herpetic neuralgia in clinical trials is mainly caused by selection bias; severe cases of post-herpetic neuralgia (eg, older patients with severe pain and rash) are more likely to be referred to a hospital and enrolled in trials. In the study by Helgason et al, the prevalence of post-herpetic neuralgia at 3 months among patients $>60$ years of age $(20 \%)$ was similar to that observed among 181 patients of the same age in the placebo arm of a clinical trial $(24 \%){ }^{3}$

Although individual trials suggest that antiviral drugs (famciclovir and valaciclovir) reduce the prevalence of postherpetic neuralgia by as much as $50 \%$, a recent metaanalysis suggests a more conservative treatment effect. ${ }^{2}$

If antiviral treatment reduces post-herpetic neuralgia by $25 \%$ (which needs to be confirmed), then treating all 421 patients in the study of Helgason $e t$ al would have reduced post-herpetic neuralgia at 1 month from $19 \%$ to $14.25 \%$ (absolute risk reduction [ARR] $4.75 \%, \mathrm{n}=20$, number needed to treat $[\mathrm{NNT}]=21$ ); at 3 months, from $7 \%$ to $5.25 \%(\mathrm{ARR}=1.75 \%, \mathrm{n}=7, \mathrm{NNT}=57)$; and at 1 year, from $3 \%$ to $2.25 \%(\mathrm{ARR}=0.75 \%, \mathrm{n}=32, \mathrm{NNT}=133)$. Restricting antiviral treatment to the 115 patients $>60$ years of age would reduce post-herpetic neuralgia at 3 months from $20 \%$ to $15 \%(\mathrm{ARR}=5 \%, \mathrm{n}=6, \mathrm{NNT}=20)$, saving 6 patients from post-herpetic neuralgia at 3 months compared with 7 patients if all patients were treated.

This study highlights that herpes zoster is benign for most patients and that treatment of all patients with antiviral treatment is unnecessary. Further research is needed to identify more precisely the few patients who will have severe post-herpetic neuralgia and whether antiviral treatment really is effective for them (and if so, how effective and with which agent, what dose, and for how long).

Graeme J Hankey, MBBS

Royal Perth Hospital, Perth, Western Australia, Australia

1 Choo PW, Galil K, Donahue JG, et al. Risk factors for postherpetic neuralgia. Arch Intern Med 1997;157:1217-24.

2 Wood MJ, Kay R, Dworkin RH, et al. Oral acyclovir therapy accelerates pain resolution in patients with herpes zoster: a meta-analysis of placebo-controlled trials. Clin Infect Dis 1996;22:341-7.

3 McKendrick MW, McGill JI, Wood MJ. Lack of effect of acyclovir on postherpetic neuralgia. BMJ 1989;298:431. 